\title{
Flameless errekuntzak klima aldaketaren aurka
}

\section{(Flameless combustion against climate change)}

\author{
Naiara Romero-Anton*, Koldobika Martin-Eskudero, \\ Luis Alfonso del-Portillo-Valdés
}

Ingenieritza Energetikoa Saila. Bilboko Ingeniaritza Eskola (UPV/EHU)

\begin{abstract}
LABURPENA: Gaur egun klima aldaketaren inguruan daukagun egoera hobetzeko, energia kontsumoa murriztu behar da eta teknologia eraginkorrak eta emisiorik gabekoak suspertu behar dira. Nahiz eta energia berriztagarrien alde apustu egin, gaur egungo datuen arabera, bai gaur egun zein etorkizunean erregai fosilen kontsumoa energia primarioa izango da. Egoera honen aurrean erregai fosiletan oinarritzen diren teknologiei buruz ikerkuntzak egitea beharrezkoa da, teknologia berderantz bideratzeko. Klima aldaketari aurre egiteko flameless errekuntza garatu da. Flameless errekuntza produktuen aerodinamikan oinarritzen da, eta horiek birzirkulatuz erreaktiboak diluitu egiten dira. Horri esker $\mathrm{O}_{2}$-aren kontzentrazioa murrizten da labeko gar tenperatura murriztuz. $\mathrm{NO}_{x}$ gasen emisioak tenperaturarekin erlazionatuta daudenez, labe tenperatura murriztean, $\mathrm{NO}_{\mathrm{x}}$ emisioak murrizten dira. Gainera, produktuen birzirkulazioaren bitartez erreaktiboak aurreberotzen badira, energia eraginkortasuna hobetzen da. Teknologia berri horrek aplikazio zuzena izan dezake tenperatura altuko labe eta galdaretan; adibidez, potentzia termikoko instalazioetan, findegietan, industria kimikoan, zeramika, beira, zementu eta altzairu lantegietan, $\mathrm{NO}_{\mathrm{x}}$ emisioak eta energia kontsumoa murriztuz. Flameless teknologia hobeto ulertzeko helburuarekin ikertzaileak Fluido Dinamika Konputazionala (FDK)-ren bitartez esperimentuak eta simulazioak egiten ari dira. FDK programan dauden modeloekin ohiko errekuntzaren ezaugarriak zehaztasunez simula daitezke (bero transferentzia, jariakinen mekanika, erradiazio termikoa, erreakzio kimikoak eta turbulentzia-kimika interakzioa), baina ez flameless errekuntza, erreaktiboen diluzioa kontuan hartzen ez delako. Hori dela eta beste modelo berri batzuk garatu behar dira.
\end{abstract}

HITZ GAKOAK: Flameless errekuntza, $\mathrm{NO}_{\mathrm{x}}$ emisioak, eraginkortasun energetikoa, klima aldaketa.

ABSTRACT: In order to improve nowadays climate change situation, energy consumption must be reduced and efficient and no-pollution technologies should be promoted. Although huge effort is made toward renewable energy technologies, according to nowadays data, today and in the near future fossil fuels consumption will be the primary source energy. Due to that, it is necessary to research in fossil fuel technologies in order to be more climate friendly. Flameless combustion was developed against climate change. Flameless combustion is based on the aerodynamic recirculation of flue gas, which diluted reactants. The dilution effect reduces $\mathrm{O}_{2}$ concentration and consequently furnace temperature is reduced. $\mathrm{NO}_{x}$ emissions are directly related with furnace temperature, so that, once furnace temperature is reduced $N O_{x}$ emissions go down. Additionally, reactants can be preheated by recirculated product increasing energy efficiency. This new technology has a direct application in high temperature furnaces as well as in boilers; as example, thermal power plants, refineries, chemical industry, ceramic, glass, cement and steel factories, reducing NOx emissions and energy consumption. In order to understand better flameless combustion researches are working on experimental set-ups as well as on Computational Fluids Dynamics (CFD) modelling. The CFD's models simulate accurately conventional combustions characteristics; heat transfer, fluids dynamics, thermal radiation, chemical reactions and turbulence-chemistry interaction, but not flameless combustion as reactant dilution is not considered. Consequently, new models must be developed for better simulation of flameless combustion.

KEYWORDS: Flameless combustion, $\mathrm{NO}_{x}$ emissions, energy efficiency, climate change.

* Harremanetan jartzeko / Corresponding author: Naiara Romero-Anton. Ingenieritza Energetikoa Saila. Bilboko Ingenieritza Eskola, UPV/EHU, Ingeniero Torres Quevedo Enparantza, 1 (48013 Bilbo-Bizkaia, Euskal Herria). - naiara.romero@ehu.eus https://orcid.org/0000-0001-5044-6391.

Nola aipatu / How to cite: Romero-Anton, Naiara; Martin-Eskudero, Koldobika, Del-Portillo-Valdés, Luis Alfonso (2021). «Flameless errekuntzak klima aldaketaren aurkan; Ekaia, 39, 2021, 299-311. (https://doi.org/10.1387/ekaia.21753)

Jasoa: 2020, maiatzak 25; Onartua: 2020, irailak 22.

ISSN 0214-9001 - elSSN 2444-3255 / (c) 2021 UPV/EHU 


\section{SARRERA}

Gaur egungo gizartea energiaren kontsumoaz jabetzen ari da, baina orain dela 20 urte, gizartearen kezka hauxe zen: zelan lor dezakegu energia gehiago lurzorutik? Gaur egun egoera aldatu egin da, eta gizartearen kezka beste hau da: zelan lortu energia inguruneko poluzioa minimizatuz? Nahiz eta gizarteak ahaleginak egin energiaren kontsumoa gutxitzeko, Energia Departamenduak (ED) argitaratutako datuen arabera, 2012-2040 urte bitartean, energiaren kontsumoa \% 48 handituko da [1] Ekonomia Lankidetza eta Garapenerako Erakundean (ELGE) parte hartzen ez duten herrialdeengatik («Non-OECD» deituak), hala nola Indiagatik eta Txinagatik (1. irudia).

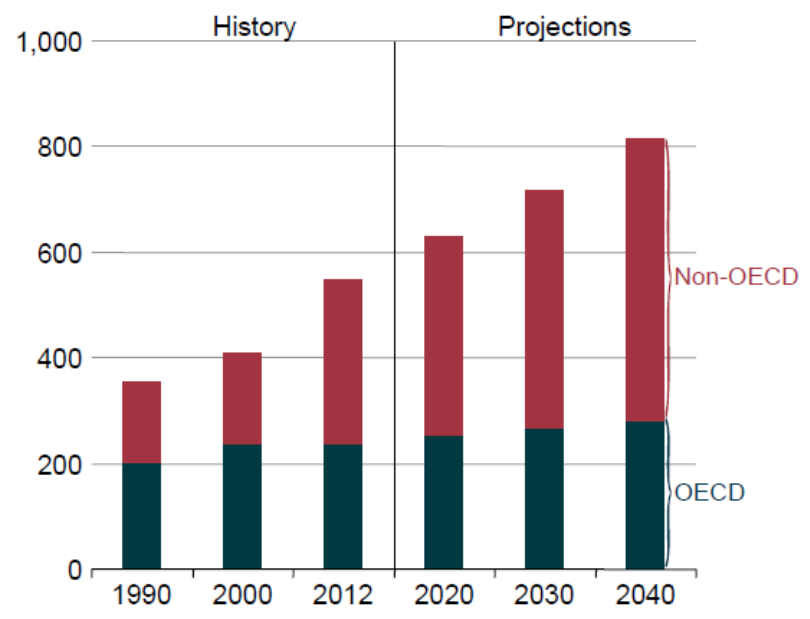

1. irudia. Munduko energiaren kontsumoa 1990-2040 (kuatriloi BTU). ARG.: EIA [1].

Energiaren eskaria hornitzeko erabiltzen den energia iturria aztertzean, ikus daiteke, bai gaur egun eta bai etorkizunean, energiaren kontsumo gehiena erregai fosilen errekuntzaz hornitzen dela eta hornituko dela [2]. Hurrengo irudian, munduko energiaren kontsumoa vs energia iturria ehunekotan ikus daiteke.

Gaur egun energia berriztagarrien alde apustua egin bada ere, 2. irudian antzeman daitekeen moduan, energiaren eskaera instalazio berrien kapazitatea baino arinago handitzen ari da, eta 2040. urterako energia berriztagarrien hornikuntza $\% 4$ soilik handitzea espero da, kontsumo totalaren $\% 23$ izanda. Bestalde, datuen arabera, petrolioaren kontsumoa ia konstante mantenduko da, ikatzaren kontsumoa \% 3 murriztuko delarik (ondo dagokiona $\mathrm{CO}_{2}$ emisioetarako); gas naturalaren kontsumoa, ordea, \% 2 handituko da, eta energia nuklearraren kontsumoa konstante mantenduko da [2]. 
Flameless errekuntzak klima aldaketaren aurka

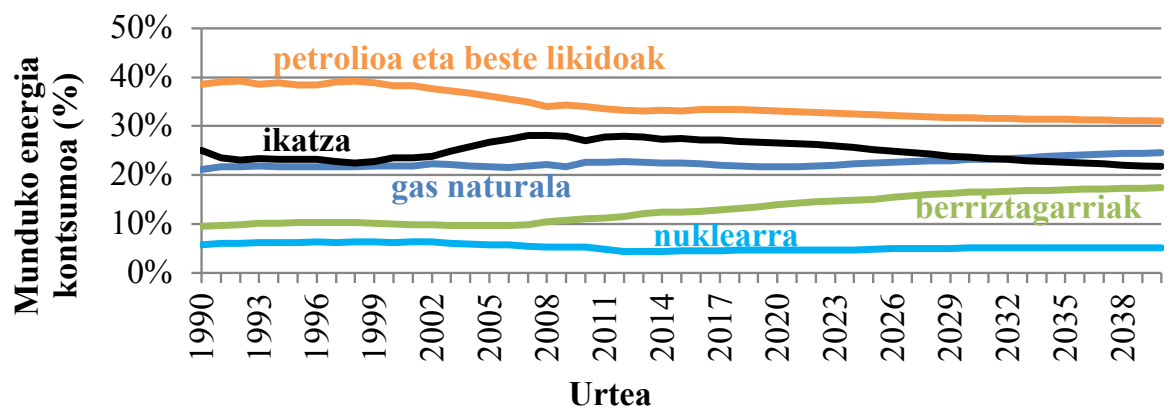

2. irudia. Munduko energiaren kontsumoa ehunekotan energia iturriaren arabera. ARG.: Propioa. Datuak EIA [2].

Azkenik, ondoriozta daiteke munduan kontsumitzen den energiaren $\% 80$ baino gehiago erregai fosilen errekuntzatik datorrela; beraz, esan daiteke energia iturri primarioa dela. Erregai fosilek sorturiko berotegi-efektuko gasak murrizteko, garrantzi handikoa da errekuntza sistemen eraginkortasuna handitzea [3], eta horretarako errekuntza teknika berrien inguruan ikertu behar da.

\section{ERREKUNTZA EMISIOAK MURRIZTEKO TEKNOLOGIAK}

Errekuntzaren inguruko ikerkuntza orain dela urte asko hasi zen, gizartearen teknologia zaharrenetako bat baita. Gaur egun, errekuntza maiz erabiltzen da energia primarioa transformatuz beste energia mota batzuk lortzeko, eta arlo askotan erabiltzen da, esaterako, mugikortasunean eta garraioetan, elektrizitatearen ekoizpenean, enpresetan eta etxeetan.

Errekuntzan askatutako beroak prozesu zaila eta berezia egiten du. Zergatik? Beroa askatu ahala tenperatura igotzen delako erreakzio abiadura handituz, prozesu ez-lineal bat sortuz. Errekuntzak fluidoen mekanika eta kimika konbinatzen ditu; beraz, fenomeno multifisikoa eta multieskalakoa da. Multifisikoa da, arlo desberdinek parte hartzen dutelako (esaterako, kimika, erradiazio termikoa, fluidoen mekanika eta akustika), eta multieskalakoa da, nahasketaren denbora eskala $\left(\tau_{t}\right)$ eta kimikaren denbora eskala $\left(\tau_{\mathrm{c}}\right)$ kontuan hartu behar direlako. Hori dela eta, errekuntzaren kalkuluak sinplifikatzeko, dimentsiorik gabeko zenbaki berriak garatu dira; adibidez, Damköler (Da) zenbakia eta Karlovitz (Ka) zenbakia.

Errekuntzaren produktuek inpaktua dute airearen kutsaduran $\left(\mathrm{CO}, \mathrm{SO}_{2}\right.$, $\mathrm{NO}_{2}, \mathrm{O}_{3}$, partikulak) eta berotegi efektuan $\left(\mathrm{CO}_{2}, \mathrm{CH}_{4}, \mathrm{~N}_{2} \mathrm{O}\right.$, halokarbonoak). Fourierrek, 1824. urtean, lehenengo aldiz proposatu zuen atmosferako gasak zirela lurreko tenperaturaren goratzearen eragileak. Geroago, 
1896. urtean, estimatu zen $\mathrm{CO}_{2}$ emisioak bikoiztearen ondorioz Lurraren tenperatura $5-6{ }^{\circ} \mathrm{C}$ igoko zela [4], gaur egun gertatzen den bezala. Baina 1997. urtera arte itxaron behar izan zen Europar Batasunak (EB) emisioak kontrolatzeko araudiak lantzeko. Kyotoko Protokoloa 1997. urtean sinatu zen, baina 2005. urtera arte ez zen indarrean ipini. Geroago, 2015eko Pariseko Hitzarmenean, Kyotoko Protokoloa indarrean mantentzea erabaki zen, klima aldaketaren mugak mantenduz.

Klima aldaketa murrizteko helburuarekin teknologia desberdinak ikertzen ari dira. Horietako bat hidrogeno ekonomian oinarritzen da; hau da, hidrogenoak ordezko erregaiaren rola hartzen du garraio sektorean eta etxebizitzetan [4] [5] [6]. Hidrogenoa ere erabiltzen da energia berriztagarrietatik sortutako elektrizitatea metatu eta garraiatzeko, hidrogenoaren elektrolisiaren bitartez eta Liquid Organic Hydrogen Carriers (LOHC) izeneko metodoaren bitartez. Adibide moduan 3. irudian hidrogeno ekonomiaren eskema bat erakusten da.

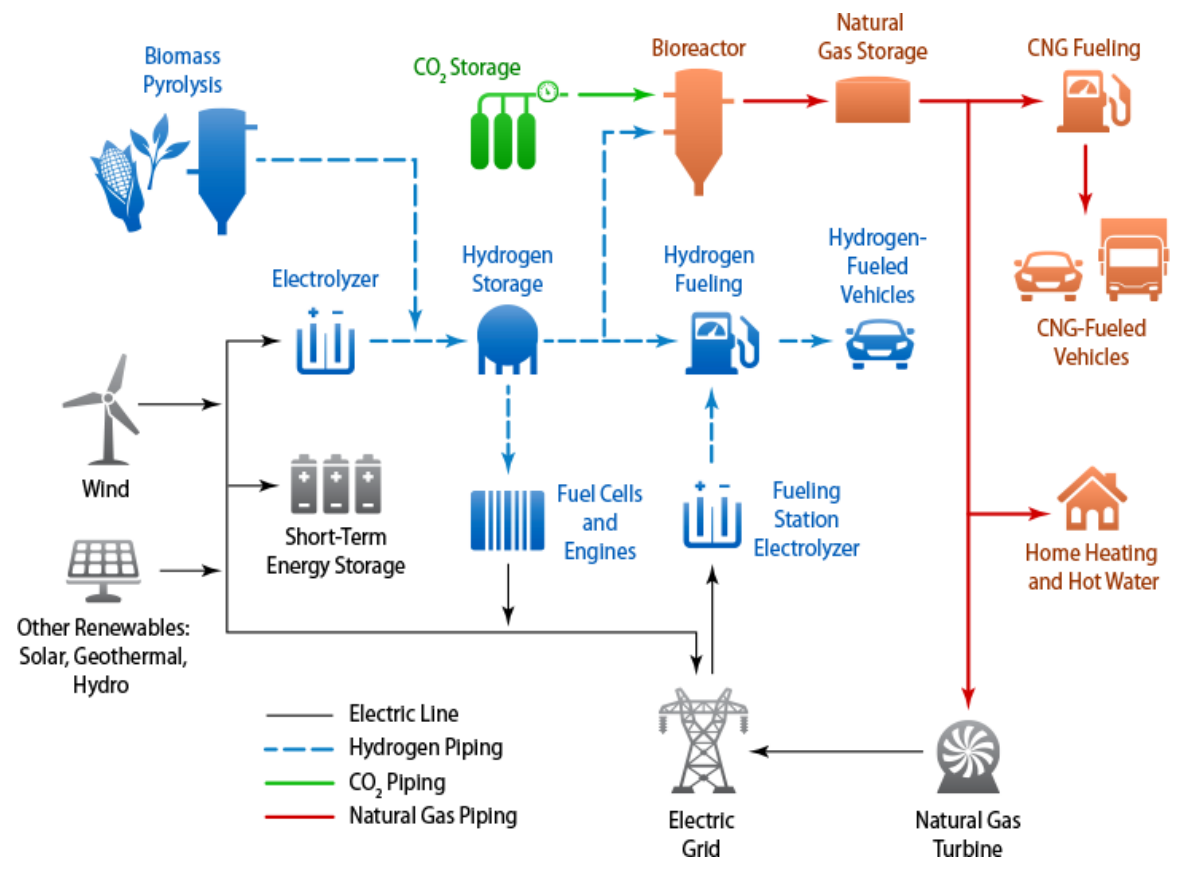

3. irudia. Hidrogeno ekonomiaren eskema. ARG.: NREL [7].

Carbon Capture and Storage (CCS) beste teknologia bat da berotegi efektuko gasak murrizteko (4. irudia) eta hiru eratan aplika daiteke: posterrekuntzaren hartzea (iragazketa hezeaz) [8], aurreerrekuntzaren hartzea 
(Singas izeneko nahasketa baten bitartez) [9] eta oxyfuelaren hartzea (nitrogenorik gabeko errekuntza) [10].

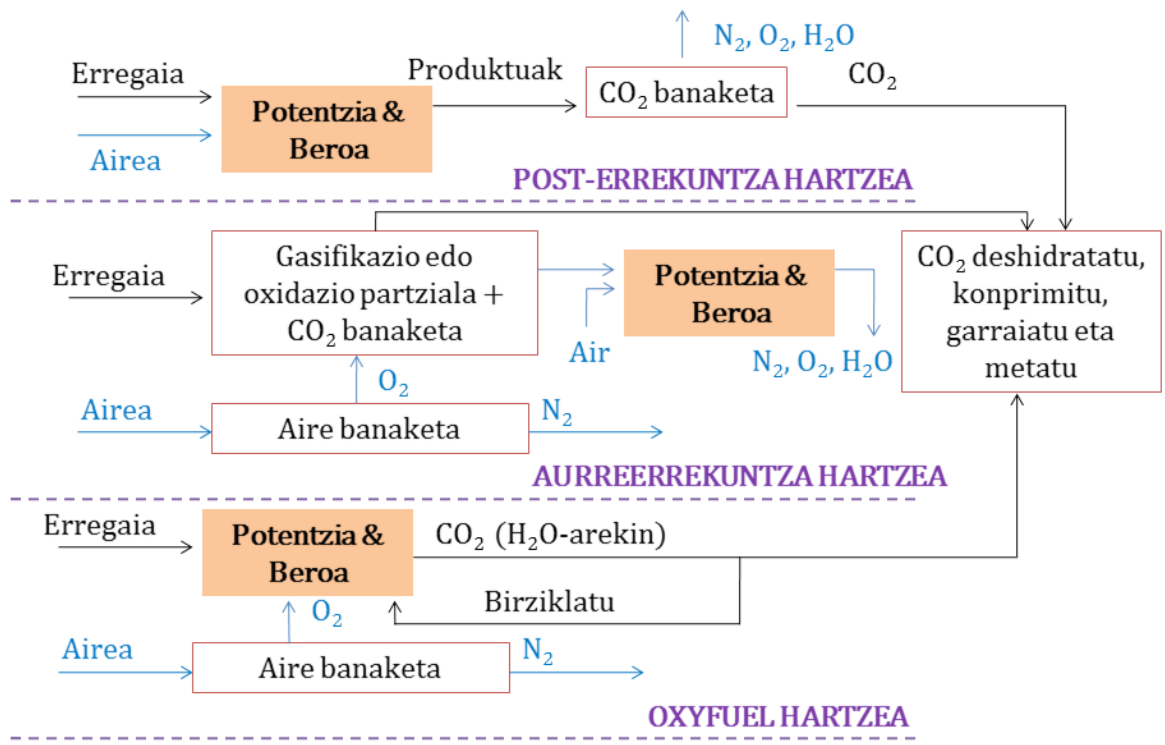

4. irudia. $\mathrm{CO}_{2}$-aren metaketako teknologia nagusiak. ARG.: Propioa.

Bioerregaiak erabiltzea, bioetanola eta biodiesela nagusiki, beste aukera bat da erregai fosilak ordezkatzeko klima errespetatuz. Dena den, bioerregaiak azukretik, almidoitik eta landare olioetatik ekoizten dira, baserri lurrak okupatuz eta ura eta lurzorua zeharka kutsatuz, ongarri eta pestiziden bitartez. Bestalde, ikertzaile batzuek ondorioztatu dute bioerregaien kostua ohiko erregaiena baino altuagoa dela [11]. Hala ere, ikerkuntzak egiten ari dira bioerregaiak barne-errekuntzako motorretan erabiltzeko [12].

Bukatzeko, berotegi efektuko gasen emisioa murrizteko azken aukera errekuntza-eraginkortasuna hobetzea da [13]. Errekuntza-eraginkortasuna handitzeak erregaiaren kontsumoa murrizten du, eta horrekin batera $\mathrm{CO}_{2}$ eta $\mathrm{NO}_{\mathrm{x}}$ gasen emisioak ere bai. Hori dela eta, errekuntza teknologia berrien garapena beharrezkoa da. Ildo horretan, Injekzio Pobre Zuzena (IPZ) ikertzen ari da hegazkineko turbinetan [14], autoen sektorean Karga Homogeneoko Konpresio Piztea (KHKP) [15], Gasifikazio Integratuko Ziklo Konbinatuetan (GIZK) oxy-coal errekuntza (oxyfuelen kasu bat) [16], eta flameless izeneko errekuntza [17]. Flameless errekuntza berotegi efektuko gasak murrizten dituen teknologia oso interesgarria da, errekuntza-eraginkortasuna hobetzeaz gainera $\mathrm{NO}_{\mathrm{x}}$ emisioak murrizten dituelako. 
Naiara Romero-Anton, Koldobika Martin-Eskudero, Luis Alfonso del-Portillo-Valdés

\section{FLAMELESS ERREKUNTZA}

Flameless errekuntza labe barruko produktuen birzirkulazioaren aerodinamikan oinarritzen da. Errekuntza horretan erregai eta aire lasterrak diluitu egiten dira birzirkulatutako produktuen bitartez. Horren ondorioz, erreaktiboen kontzentrazioa $\left(\mathrm{O}_{2}\right.$-arena batez ere) murrizten da, eta, beraz, erreakzio-abiadurak murrizten dira, errekuntza-ganberaren tenperatura altuko eremuak saihestuz eta gar tenperatura murriztuz (ohiko errekuntzarekin konparatuta). $\mathrm{NO}_{\mathrm{x}}$ eraketaren tasa tenperatura altuetan handitzen da. Beraz, $\mathrm{NO}_{\mathrm{x}}$ emisioak mugatu daitezke tenperatura baxuari eutsiz. Flameless errekuntzan gar tenperatura ohiko errekuntzan baino baxuagoa denez, $\mathrm{NO}_{\mathrm{x}}$ gasen emisioak murrizten dira teknologia horren bitartez. Aldi berean, birzirkulatutako produktuak erabiltzen dira erreaktiboak aurreberotzeko. Hori dela eta, bi hobekuntza lortzen dira ohiko errekuntzarekin alderatuta; (1) errekuntza-eraginkortasuna hobetzen da (aurreberoketari esker), eta (2) $\mathrm{NO}_{\mathrm{x}}$ emisioak murrizten dira, errekuntzan askatzen den beroaz birzirkulatutako produktuak berotzen dira disipadore termikoaren papera hartuz. Ondorioz, gar tenperatura murrizten da, eta zuzenean $\mathrm{NO}_{\mathrm{x}}$ emisioak ere murrizten dira. Aldi berean, errekuntza-eraginkortasuna hobetzean, erregaiaren kontsumoa murrizten da, eta, alde horretatik, $\mathrm{NO}_{\mathrm{x}}$ eta $\mathrm{CO}_{2}$ gasen emisioak ere murriztea lortzen da. Flameless eta ohiko errekuntzen arteko aldeak azpimarratzeko, 5. irudian gar tenperatura eta erreaktiboen tenperaturak adierazi dira.

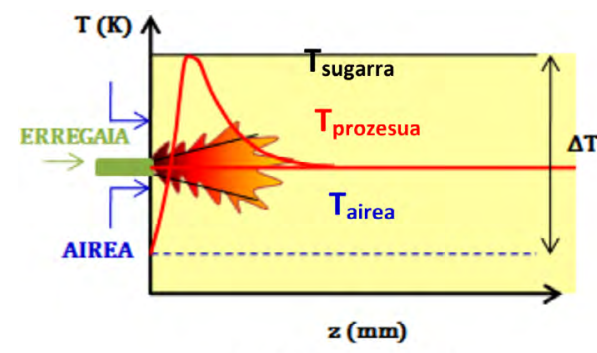

a) Ohiko errekuntza

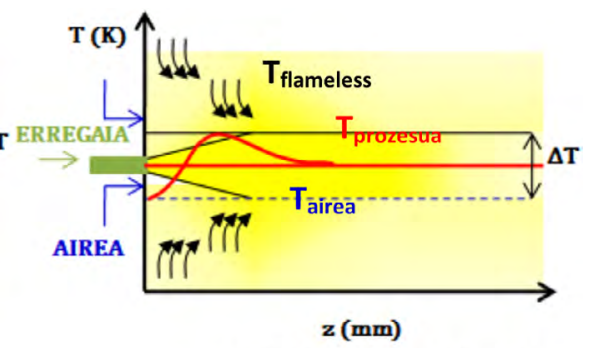

b) Flameless errekuntza

5. irudia. Ohiko errekuntzaren eta flameless errekuntzaren tenperatura banaketa. ARG.: Propioa.

Ohiko errekuntzan tenperatura banaketan gailur bat agertzen da. Aldiz, flameless errekuntzan gailurra askoz ahulagoa da. Ohiko errekuntzan garraren muga nabaria da; flameless errekuntzan, berriz, ez dago; hori dela eta, garrik gabeko errekuntza horri flameless izena eman zaio. Flameless errekuntzan, 5. irudian, birzirkulazioa eta airearen aurreberoketa nabaritzen dira. Laburpen moduan hurrengo taulan flameless eta ohiko errekuntzen ezaugarriak agertzen dira. 
1. taula. Ohiko eta flameless errekuntzen arteko konparaketa. ARG.: Propioa.

\begin{tabular}{|c|c|c|}
\hline Ezaugarriak & Ohiko errekuntza & $\begin{array}{l}\text { Flameless } \\
\text { errekuntza }\end{array}$ \\
\hline Gar tenperatura & $\begin{array}{c}\text { Altua (gar tenperatura } \\
\text { adiabatikotik hurbil) }\end{array}$ & baxuagoa $\approx 1500 \mathrm{~K}$ \\
\hline Tenperatura banaketa uniformea & $\boldsymbol{x}$ & $\checkmark$ \\
\hline Errekuntza produktuen birzirkulazioa & $\mathbf{x}$ & $\checkmark$ \\
\hline Turbulentzia intentsitatea eta zinetika & $\downarrow \downarrow$ & $\uparrow \uparrow$ \\
\hline Gar ikusgaia & $\checkmark$ & $\boldsymbol{x}$ \\
\hline Gar egonkorra & $\downarrow \downarrow$ & $\uparrow \uparrow$ \\
\hline Diluitutako erreaktiboak & $\boldsymbol{x}$ & $\checkmark$ \\
\hline Aurreberotutako erreaktiboak & $\boldsymbol{x}$ & $\checkmark$ \\
\hline $\mathrm{O}_{2}$ kontzentrazioa & $\uparrow \uparrow$ & $\downarrow \downarrow$ \\
\hline Soinu-intentsitatea & $\uparrow \uparrow$ & $\downarrow \downarrow$ \\
\hline $\mathrm{NO}_{\mathrm{x}}$ emisioak & $\uparrow \uparrow$ & $\downarrow \downarrow$ \\
\hline Eraginkortasuna & $\downarrow \downarrow$ & $\uparrow \uparrow$ \\
\hline
\end{tabular}

Taula aztertu ondoren ondoriozta daiteke flameless errekuntzak: (1) tenperatura banaketa uniformea duela labearen baitan, (2) gar egonkorragoa duela, (3) soinu-intentsitatea murrizten duela, (4) $\mathrm{NO}_{\mathrm{x}}$ emisioak murrizten dituela eta, bukatzeko, (5) eraginkortasun energetikoa hobetzen duela.

\section{FLAMELESS ERREKUNTZAREN APLIKAZIOAK}

Ez dago zalantzarik flameless errekuntza teknologia eraginkorra dela eta ingurumena errespetatzen duela. Beraz, interesa handia dauka industria aplikazioetan, adibidez, potentzia termiko instalazio, findegi, industria kimiko, zeramika, beira, zementu eta altzairu lantegietan. Aplikazio horietan energia altuko errekuntzak izaten dira, non energia aurrezpenak eta emisio murrizketak lor baitaitezke flameless errekuntza aplikatuz gero.

Flameless errekuntza tenperatura altuko labeetan ikertzen hasi zen Japonian, 1990. urtean, $\mathrm{NO}_{\mathrm{x}}$ emisioak murrizteko helburuarekin [18]. Geroago, Alemanian, Flameless Oxidation (FLOX) erregailuak aztertu ziren [17]. Flameless errekuntza tamaina handiko labeetan aplikatzen denean, errekuntza gasak edo produktuak erreaktiboak berotzeko erabili behar dira (autosutze tenperaturaren gainetik). Horri esker energia eraginkortasuna handitzea eta erregaia aurreztea lortzen dira. Aldi berean, erreaktiboak diluitzen direnez $\left(\mathrm{O}_{2}\right.$ maila $<\%$ 15) gar tenperatura baxuagoa lortzen da (eta $\mathrm{NO}_{\mathrm{x}}$ emisioak murriztu). Ikerkuntzetatik ere ondorioztatu zen, tenperatura banaketa homogenoa lortzen dela labearen barruan. Kulamar et al. [19] es- 
perimentuek erakutsi zuten flameless errekuntzako tenperatura aldaketa $\% 15$ dela, ohiko errekuntzako tenperatura aldaketa \% 50 izanik. Bestalde, erreaktiboak aurreberotuta daudenez, errekuntzak egonkortasun hobea erakusten du, eta horri esker abiadura handiagoko erreaktibo lasterrak erabil daitezke. Ezaugarri horiek bero transferentzia uniforme eta zabalagoa suspertzen dute, energia aurrezteko aukerekin. Adibide moduan, Wünning \& Wünning [17] ikertzaileek simulazioak egin zituzten, hiru errekuntza sistemetan, Fluidoen Dinamika Konputazionala (FDK) erabiliz, $160 \mathrm{~kW}$ termiko (kWth) lortzeko asmoz. Lehenengo errekuntza sistema aire aurreberoketarik gabeko erregailua izan zen, beharrezko potentzia $400 \mathrm{~kW}$ zelarik. Bigarren sistemak beroa berreskuratzeko sistema bat erabiltzen zuen, airea $600{ }^{\circ} \mathrm{C}$-an aurreberotzeko. Kasu horretan beharrezko potentzia $245 \mathrm{~kW}$ zen (baina $\mathrm{NO}_{\mathrm{x}}$ emisioak handitzen ziren erreaktiboak diluitzen ez zirelako eta labeko tenperatura handitzen zelako). Bukatzeko, FLOX sistema bat (flameless erregailua) modelatu zen, non airea $950{ }^{\circ} \mathrm{C}$-ra aurreberotzen zen. Erregailuak $200 \mathrm{~kW}$ kontsumitzen zituen, eta aurreko kasuekin konparatuz erregaia aurreztu eta $\mathrm{NO}_{\mathrm{x}}$ emisioak murrizten ziren, aplikazio honetan erreaktiboak diluitzen direlako. Azken kasu horretan aurreberogailu bat erabili izan balitz, airea $950{ }^{\circ} \mathrm{C}$-ra aurreberotzeko errendimendu energetiko berdina lortuko zen. Hala ere, labeko tenperatura handituko zenez, $\mathrm{NO}_{\mathrm{x}}$ emisioak handituko ziren (flameless erregailuak $\mathrm{NO}_{\mathrm{x}}$ emisioak murrizten ditu). Flameless errekuntzak errendimendu energetikoa hobetzea ahalbidetzen du errekuntzako produktuek tenperatura altuak dituztenean; produktuen tenperatura baxua denean, adibidez, etxeetako galdarak berotzen duen uraren kasuan, airearen aurreberotzea ahula da, eta efizientziaren hobekuntza handirik ez da lortzen.

Beraz, flameless errekuntzak industria aplikazioetan duen potentziala ikusita, simulazio eta esperimentu hauek egin dira soilik eskala handiko labeetan (begiratu 2. taula): Royal Institute of Technology (KHT) institutuak $200 \mathrm{~kW}_{\mathrm{th}}$-ko labe erdi-industrial bat simulatu zuen (STAR-CD FDK programaren bitartez) [20]; International Flame Research Foundation (IFRF) izeneko fundazioak $1000 \mathrm{~kW}_{\text {th }}$-kolabea aztertu zuen (ANSYS Fluent programaren bitartez) [21]; Mons-ko Unibertsitateak gas naturaleko $200 \mathrm{~kW}_{\text {th }}$-ko labea ikertu zuen (ANSYS Fluent programa erabiliz) [22]; NKK altzairu korporazioak, Japonian, ANSYS Fluent FDK programa ere erabili zuen flameless errekuntza hobeto ulertzeko [23], eta, bukatzeko, Delft University of Technology (DUT), erregailu anitzeko $300 \mathrm{~kW}_{\mathrm{th}}$-ko labea FDK bitartez aztertu zuen [24].

Aurreko lanen simulazioetan erabili zituzten turbulentzia-kimikako interakzio modeloak eredu matematiko sinpleetan oinarrituta daude; Eddy Dissipation (ED) modeloa, Finite Rate (FR) modeloa eta Eddy Break Up (EBU) modeloa. Halaber, mikro-nahasketan oinarritutako bi modelo erabili izan dira; Probability Density Function (PDF) eta Eddy Dissipation Con- 
cept (EDC) modeloak. Aurreko lanen simulazio emaitzak datu esperimentalekin konparatzerakoan, kasu guztietan tenperatura gainestimatzen da. Hori gertatzen da, komentatutako modeloak sinpleak izateaz aparte ohiko errekuntzarako garatuak izan direlako, hau da, flameless errekuntzako erreaktiboen diluzioa kontuan hartu barik.

2. taula. Simulazio numerikoak labe industrialetan. ARG.: Propioa.

\begin{tabular}{c|c|c|c|c|c}
\hline Erref. & $\begin{array}{c}\text { Turbulentzia } \\
\text { modeloa }\end{array}$ & $\begin{array}{c}\text { Mekanismo } \\
\text { kimikoa }\end{array}$ & $\begin{array}{c}\text { Turbulentzia-kimika } \\
\text { interakzioa }\end{array}$ & Erradiazioa & $\begin{array}{c}\text { Neurketa } \\
\text { teknika }\end{array}$ \\
\hline KHT & $\begin{array}{c}\text { Estandar } \\
\mathrm{k}-\varepsilon\end{array}$ & 2-urratsa & ED/FR & DTM & $\begin{array}{c}\text { Intrusibo } \\
\text { Elementuak \& } \\
\text { Termoparea }\end{array}$ \\
\hline IFRF & $\begin{array}{c}\text { Estandar } \\
\mathrm{k}-\varepsilon\end{array}$ & 2 -urratsa & $\begin{array}{c}\beta \text {-PDF oreka B-PDF } \\
\text { flamelet, EBU }\end{array}$ & DO & $\begin{array}{c}\text { Intrusibo } \\
\text { Elementuak \& } \\
\text { Termoparea } \\
\text { LDA }\end{array}$ \\
\hline MONS & $\begin{array}{c}\text { Estandar } \\
\mathrm{k}-\varepsilon\end{array}$ & 1 -urratsa & $\begin{array}{c}\beta \text {-PDF oreka, } \\
\text { ED/FR }\end{array}$ & DO & $\begin{array}{c}\text { Intrusibo } \\
\text { Elementuak \& } \\
\text { Termoparea } \\
\text { CCD kamera } \\
\text { OH neurtzeko }\end{array}$ \\
\hline NKK & $\begin{array}{c}\text { Estandar } \\
\mathrm{k}-\varepsilon\end{array}$ & 15 espezie & $\beta$-PDF oreka & P1 & $\begin{array}{c}\text { Intrusibo } \\
\text { Elementuak \& } \\
\text { Termoparea }\end{array}$ \\
\hline DUT & $\begin{array}{c}\text { Realizable } \\
\mathrm{k}-\varepsilon\end{array}$ & 16 espezie & EDC & DO + WSGGM & $\begin{array}{c}\text { Intrusibo } \\
\text { Elementuak \& } \\
\text { Termoparea }\end{array}$ \\
\hline
\end{tabular}

Flameless errekuntza tamaina handiko labeetan aztertzea zaila eta konplexua da, alde batetik, datu esperimentalak izatea zaila delako, izaten diren tenperatura altuengatik eta, bestalde, FDKren ikuspuntutik denbora konputazional handia behar delako simulazioak egiteko.

Komentatutako zailtasunak aztertu ondoren, flameless errekuntza teknologiaren bideragarritasuna aztertzeko, ikertzaileak esperimentuak egiten ari dira laborategi tamainako labeetan, eta eskuraturiko datuen bitartez FDK simulazioak egiten ari dira. Horri esker jakin da ohiko errekuntzarako zehatzak diren turbulentzia-kimikako modeloak ahulak direla flameless errekuntzarako (adibide moduan begiratu 6. irudira). Beraz, erreaktiboen diluzioa kontuan hartzen duten turbulentzia-kimikako modeloak garatu behar dira. 
Naiara Romero-Anton, Koldobika Martin-Eskudero, Luis Alfonso del-Portillo-Valdés
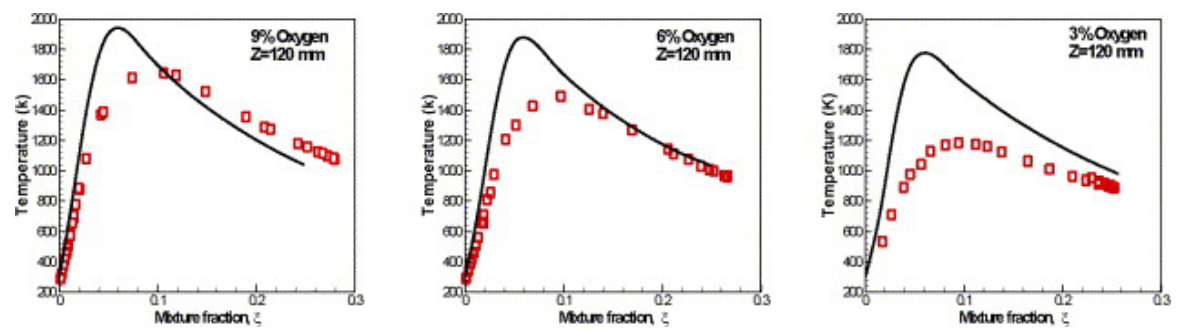

6. irudia. Batez besteko tenperaturaren balioa $\mathrm{O}_{2}$ kontzentrazio desberdinetarako. Lerro beltza EDC modeloaren bitartez iragarritakoa eta lauki gorriak datu esperimentalen balioak. ARG. [25].

\section{ONDORIOAK}

Gaur egun klima-aldaketaren inguruan dagoen ardura kontuan izanda, energiaren kontsumoa murrizteko ahaleginak egiten ari dira. Bestalde, ondorioztatu da erregai fosilen errekuntza energiaren kontsumo primarioa dela, bai gaur egun, bai etorkizunean. Beraz, energiaren kontsumoa murriztea zaila denez, eta erregai fosilen kontsumoak indarrean jarraitzen duela ikusita, ikertzaileak errekuntza teknologia berrietan lan egiten ari dira.

Flameless errekuntza teknologia interesgarria dela ondorioztatu da eraginkortasun energetikoa hobetzeaz aparte, $\mathrm{NO}_{\mathrm{x}}$ gasen emisioak murrizten dituelako. Beste abantaila batzuk ere baditu: gar egonkorra eta soinu-intentsitatearen murrizketa.

Flameless errekuntza hobeto aztertzeko bide bat esperimentuak egitea da. Eskala handiko labeek neurketak egiteko erakusten dituzten zailtasunak kontuan izanda, laborategi tamainako esperimentuak dira ikerkuntza arloan egiten direnak. Adibide moduan, Delft University of Technology, Aachen-go Unibertsitatean eta Mons-ko Unibertsitatean erabiltzen dira 9, 5-10 eta $30 \mathrm{~kW}$-eko erregailuak dituzten paralelepipedo itxurako labeak, hurrenez hurren.

Hala ere, flameless errekuntza-teknologia optimizatzeko, sistemaren barruan gertatzen diren fenomeno fisikoen ikuspegi sakonagoa beharrezkoa da. Esperimentuak egiteko behar den denbora eta kostu ekonomikoa kontuan izanda, flameless errekuntza hobeto ulertzeko beste irtenbide bat FDK da. Errekuntza-parametro aldakorrekin hainbat teknika probatzea ahalbidetzen du, askoz ere denbora-tarte laburragoan eta kostu baxuagoekin. Beraz, FDK flameless errekuntza aztertzeko oso tresna garrantzitsua izan daiteke. Hori dela eta, boladan dagoen flameless errekuntzaren ikerkuntza lerroa Fluidoen Dinamika Konputazionalean (FDK) oinarritzen da. FDKren bitartez atzeman daitezke errekuntzaren ondoriozko tenperatura banaketa eta 
produktuen fluxua. Horri esker, labearen diseinua optimiza daiteke hura fabrikatu aurretik.

FDK programan dauden modeloekin ohiko errekuntzaren ezaugarriak zehaztasunez simula daitezke; bero transferentzia, jariakinen mekanika, erradiazio termikoa, erreakzio kimikoak eta turbulentzia-kimikako interakzioa, baina ez flameless errekuntza, erreaktiboen diluzioa kontuan hartzen ez delako. Hori dela eta, diluitutako erreaktiboak kontuan hartzen dituzten modelo matematikoen garapena beharrezkoa da, eta ildo horretan daude abian ikerkuntzak. Ikerkuntzak, batez ere, Eddy Dissipation Concept (EDC) modeloaren hedapenean oinarritzen dira [26]. Hala ere, Flamelet Generation Manifold (FGM) modeloak eskaintzen duen denbora konputazional aurrezpena dela eta, modelo horren hedapenean ikerkuntzak abian daude flameless errekuntza FDK bitartez aztertzeko [27] [28].

Bukatzeko, flameless errekuntzaren abantailak kontuan izanda, teknologia hau jadanik aplikazio errealetan inplementatua izan da; adibidez, GRC G2 erregailua [29] flameless errekuntzan oinarritutako erregailua da $\mathrm{NO}_{\mathrm{x}}$ emisioak murrizteko.

\section{BIBLIOGRAFIA}

[1] EIA. 2016. International energy outlook 2016. Retrieved from https://www. eia.gov/outlooks/ieo/pdf/0484(2016).pdf (kontsulta: 2020ko urtarrila).

[2] EIA. 2018. International energy outlook 2018. Retrieved from https://www. eia.gov/outlooks/aeo/ (Kontsulta: 2020ko urtarrila)

[3] Romero-Anton, N., Martin-Eskudero K., del-Portillo-Valdés, L. 2019. Europar Batasuneko Energia-Testuingurua. Eraginkortasun energetikoa Industrian. Ekaia Zientzia eta Teknologia Aldizkaria, 36, 191-207.

[4] Sawyer, R. F. 2009. Science based policy for addressing energy and environmental problems. Processing on the Combustion Institute, 32, 45-56.

[5] Baroutaji, A., Wilberforce, T., Ramadan, M., \& Olabi, A. G. 2019. Comprehensive investigation on hydrogen and fuel cell technology in the aviation and aerospace sectors. Renewable and Sustainable energy Reviews, 106, 31-40.

[6] Shin, J., Hwang, W., \& Choi, H. 2019. Can hydrogen fuel vehicles be a sustainable alternative on vehicle market?: Comparison of electric and hydrogen fuel cell vehicles. Technological Forecasting and Social Change, 143, 239-248.

[7] NREL. Renewable electrolysis. Retrieved from https://www.nrel.gov/hydrogen/renewable-electrolysis.html (Kontsulta: 2020ko urtarrila)

[8] Favre, E. 2007. Carbon dioxide recovery from post-combustion processes: Can gas permeation membranes compete with absorption?. Journal of Membrane Science, 294, 50-59. 
[9] Cormos, C. 2012. Integrated assessment of IGCC power generation technology with carbon capture and storage (CCS). Energy, 42, 434-445.

[10] Wall, T., Liu, Y., Spero, C., Elliott, L., Khare, S., Rathnam, R., Yu, J. 2009. An overview on oxyfuel coal combustion-State of the art research and technology development. Chemical Engineering Research and Design, 87, 1003-1016.

[11] Cherubini, F., Bird, N. D., Cowie, A., Jungmeier, G., Schlamadinger, B., \& Woess-Gallasch, S. 2009. Energy- and greenhouse gas-based LCA of biofuel and bioenergy systems: Key issues, ranges and recommendations. Resources, Conservation and Recycling, 53, 434-447.

[12] Agarwal, A. K. 2007. Biofuels (alcohols and biodiesel) applications as fuels for internal combustion engines. Progress in Energy and Combustion Science, 33, 233-271.

[13] Romero-Anton, N., Martin-Eskudero, K., Portillo-Valdes, L.A., Gomez-Elvira, I., Salazar-Herran, E. 2018. Improvement of auxiliary BI-DRUM boiler operation by dynamic simulation. Energy, 148, 676-686.

[14] Tacina, Wey, Laing, \& Mansour, A. 2002. A low NO(x) lean-direct injection, multipoint integrated module combuster concept for advanced aircraft gas turbines. NASA/TM, 211347.

[15] Yao, M., Zheng, Z., \& Liu, H. 2009. Progress and recent trends in homogeneous charge compression ignition (HCCI) engines. Progress in Energy and Combustion Science, 35, 398-437.

[16] Buhre, B. J. P., Elliott, L. K., Sheng, C. D., Gupta, R. P., \& Wall, T. F. 2005. Oxy-fuel combustion technology for coal-fired power generation. Progress in Energy and Combustion Science, 31, 283-307.

[17] Wünning, J. A., \& Wünning, J. G. 1997. Flameless oxidation to reduce thermal no-formation. Progress in Energy and Combustion Science, 23, 81-94.

[18] Tsuji H., Gupta A. K., Hasegawa T., Katsuki M., Kishimoto K. Morita M. 2002. High temperature air combustion: From energy conservation to pollution reduction. New York: CRC Press.

[19] Kumar, S., Paul, P. J., Mukunda, H. S. 2002. Studies on a new high-intensity low-emission burner. Proceedings of the Combustion Institute, 29, 1131-1137.

[20] Weihong, Y., Wlodzimierz, B. 2006. CFD as applied to high temperature air combustion in industrial furnaces. IFRF Combust $J 200603$.

[21] Hekkens, R., Mancini, M. 2004. Non-isothermal CFD model of HEC burner and furnace. Tech. Rep. G108/2. IRFR Research Station,

[22] Lupant, D., Pesenti, B., \& Lybaert, P. 2004. Assessment of combustion models of a self-regenerative flameless oxidation burner. Mons (Belgic), $\mathrm{Fa}$ culté Polytechnique de Mons, 1-7.

[23] Ishii, T., Zhang, C., \& Hino, Y. 2002. Numerical study of the performance of a regenerative furnace. Heat Transfer Engineering, 23, 23-33.

[24] Danon, B., Cho, E. de Jong, W., Roekaerts, D. J. E. M. 2011. Numerical investigation of burner positioning effects in a multi-burner flameless combustion furnace. Applied Thermal Engineering, 31, 3885-3896. 
[25] Christo, F. C., Dally, B. B. 2005. Modeling turbulent reacting jets issuing into a hot and diluted coflow. Combustion and Flame, 142, 117-129.

[26] Romero-Anton, N., Huang, X., Bao, H., Martin-Eskudero, K., Salazar-Herran, E., \& Roekaerts, D. 2020. New extended eddy dissipation concept model for flameless combustion in furnaces. Combustion and Flame, 220, 49-62.

[27] Romero, N., Martin, K., Salazar, E., del Portillo, L. A., Roekaerts, D. 2019. On the Implementation of Diluted-Air-FGM Turbulent Combustion Model in Ansys-Fluent. $11^{\text {th }}$ Mediterranean Combustion Symposium, Tenerife, Spain, 16-20 June.

[28] Ren, M., Wang, S., Romero-Anton, N., Zhao, J., Zou, C. 2020. Numerical study of a turbulent co-axial non-premixed flame for methanol hydrothermal combustion: Comparison of the EDC and FGM models. The Journal of Supercritical Fluids, 166, 105132.

[29] Fives group. Retrieved from https://combustion.fivesgroup.com/products/ pillard-product-line/burners/gas-burners/pillard-lonoxflam-g2 .html (kontsulta: 2020ko abuztua). 